\title{
As Classificações das Matemáticas de John DeE E AdRiaAn Van ROOMEN: UM ESTUDO SOBRE A ORGANIZAÇÃO DOS CONHECIMENTOS MATEMÁticos NOS SÉCUlos XVI E XVII
}

\author{
Zaqueu Vieira Oliveira \\ Universidade Federal da Integração Latino-Americana - UNILA - Brasil \\ Isabelle Coelho da Silva \\ Pontifícia Universidade Católica de São Paulo - PUC-SP - Brasil \\ Kleyton Vinicyus Godoy \\ Universidade Federal de Lavras - UFLA - Lavras - Brasil
}

(aceito para publicação em julho de 2021)

\begin{abstract}
Resumo
Pesquisas em história da matemática têm como um de seus pressupostos reconhecer que a área de conhecimento que temos hoje não é a mesma daquelas disciplinas ou ciências consideradas como matemáticas no passado. Nesse sentido, este artigo objetiva apresentar um estudo sobre o que são as matemáticas nos séculos XVI e XVII, trazendo um olhar para algumas das classificações propostas neste período. Para tanto, são apresentadas traduções de excertos de duas obras: o diagrama do prefácio aos Elementos de Euclides, de John Dee, e um capítulo da Universae mathesis idea, de Adriaan van Roomen. Esses tratados mostram que havia, entre alguns estudiosos, uma preocupação em organizar o conhecimento científico do período, classificando como matemáticas não só as artes liberais do quadrivium, mas diversas outras artes teóricas e práticas. Embora as concepções e o pensamento matemático daquele momento tenham conexões com pensamentos da Antiguidade e dos medievais, percebemos, na verdade, que compreender o conhecimento matemático dos séculos XVI e XVII se mostra como algo complexo na medida em que as classificações são controversas e não consensuais. Os trabalhos de Dee e de van Roomen nos mostram algumas destas concepções presentes entre os matemáticos do período.
\end{abstract}

Palavras-chave: História da matemática, Classificações, Traduções, John Dee, Adriaan van Roomen. 


\title{
[The Classifications of THE MATHEMAtics OF JoHn DeE AND AdRiaAN VAN ROOMEN: A STUdy ON THE ORganizATION OF THE MATHEMATICAL KNOWLEDGE IN THE $16^{\mathrm{TH}}$ AND $17^{\mathrm{TH}}$ CENTURY]
}

\begin{abstract}
Research in the history of mathematics has as one of its presuppositions to recognize that the area of knowledge we have today is not the same as those disciplines or sciences considered as mathematics in the past. In this sense, this article aims to present a study about what mathematics are in the 16th and 17th centuries, bringing a perspective at some of the classifications proposed in this period. Therefore, translations of excerpts from two works are presented: the diagram of the preface to Euclid's Elements by John Dee and a chapter from Adriaan van Roomen's Universae mathesis idea. These treatises show that there was, among some scholars, a concern with organizing the scientific knowledge of the period, classifying not only the liberal arts of the quadrivium as mathematical, but several other theoretical and practical arts. Although the conceptions and mathematical thinking at that time have connections with ancient and medieval thoughts, we realize that understanding the mathematical knowledge of the 16th and 17th centuries is complex as the classifications are controversial and not consensual. The works of Dee and van Roomen show us some of these conceptions present among mathematicians of the period.
\end{abstract}

Keywords: History of mathematics, Classifications, Translations, John Dee, Adriaan van Roomen.

\section{Introdução}

A classificação dos conhecimentos humanos, no chamado mundo Ocidental, foi objeto de estudos de diversos estudiosos desde a Antiguidade. A diversidade de classificações ao longo da história se fundamentou a partir de diferentes parâmetros "ora por seu objeto, ora por sua finalidade, ora por seu produto, ora pela maneira de ser cognoscível" (BROMBERG, 2011, p. 184). De modo geral, na Antiguidade, os conhecimentos, que mais adiante seriam denominados científicos, estavam ligados diretamente à filosofia de modo que não era possível pensar em uma classificação das artes e das ciências sem ela (BROMBERG, 2011). Dentre as contribuições deixadas pelos Antigos, Sales (2016) destaca os trabalhos de Platão (427 a.E.C.-347 a.E.C.) e Aristóteles (384 a.E.C.-322 a.E.C.).

Na Idade Média, em diversos casos, o conhecimento passa a ser observado principalmente de modo hierárquico, buscando uma ligação entre o mundo terrestre e o divino, de forma que as ciências e as artes estavam relacionadas com a teologia. 
As artes liberais - umas das formas de classificação de conhecimento mais difundidas durante a Idade Média - têm origem na Antiguidade e estão intimamente relacionadas à discussão entre conhecimento prático e teórico, pois de tal contraste surgiram o que os romanos denominaram artes liberales e artes vulgares. Segundo Bromberg (2010, p. 13), “as artes liberais, na cultura grega, eram entendidas como artes ‘mentais' e não estavam necessariamente associadas ao trabalho manual”, se contrapondo às artes servis, como, por exemplo, as atividades exercidas pelos mercadores, pastores, marinheiros, ferreiros e carpinteiros:

“[As artes servis] tinham seu estatuto ontológico inferior às artes liberais. A principal razão repousava no fato de serem mecânicas, ou seja, de serem manuais. Alguns historiadores afirmam que as artes mecânicas chegaram a ser consideradas como aplicações das teóricas a partir do século XII, talvez pela influência de interpretações árabes da classificação aristotélica do conhecimento.” (BROMBERG, 2010, p. 21)

Uma das mais antigas classificações das artes liberais na Antiguidade encontra-se na obra de Terêncio Varro (116 a.E.C.-27 a.E.C.). No livro, agora perdido, intitulado Disciplinarum libri IX, Varro descreve sucessivamente as seguintes disciplinas: Gramática, Dialética, Retórica, Geometria, Aritmética, Astronomia, Música, Medicina e Arquitetura. A Medicina e a Arquitetura normalmente não fizeram efetivamente parte das artes liberais romanas e, mesmo em classificações medievais, elas caíram em desuso (WEISHEIPL, 1965, p. 55). A organização mais comum distribuia as sete artes em dois grupos:

"O Trivium (ou Artes Sermocinales ou Triviales) e o Quadrivium (ou Artes Reales ou Physicae, também Quadriviales). O Trivium, que significa 'o cruzamento de três caminhos', é constituído da Gramática, Retórica e Dialética (ou Lógica). Tais artes são consideradas elementares. Os assuntos matemáticos, Aritmética, Geometria, Astronomia e Música, compõem o Quadrivium que significa 'o cruzamento de quatro caminhos'. As artes do Quadrivium são consideradas intermediárias, tendo como proposta a aquisição de um nível mais alto de conhecimento na Filosofia e na Teologia." (BERTATO; D’OTTAVIANO, 2007, p. 505)

No âmbito das universidades, que surgiram ao longo dos séculos XII e XIII, após concluirem os estudos das artes liberais, os estudantes podiam continuar sua formação em Direito, Medicina ou Teologia, adquirindo o grau de doutor em uma destas "três disciplinas profissionais” (DEAR, 2001, p. 16).

O Renascimento herdou as práticas medievais, ou seja, o modelo das sete artes liberais, acrescido de inúmeras artes mecânicas que foram sendo introduzidas. Percebemos também uma matematização de muitas destas artes incluídas nas diferentes classificações das ciências. Independentemente do que se buscou em cada período, “assume-se que o 
objetivo final do sistema classificatório seja descrever a estrutura e a relação entre de seus constituintes”, neste caso, as ciências (BROMBERG, 2011).

Darnton destaca que, "reordenar o trivium e o quadrivium, as artes liberais e mecânicas, os studia humanitatis e todos os ramos do antigo currículo" (DARNTON, 1986, p. 250) foi, para alguns, uma problemática considerada bastante importante na medida em que gerou intensos debates em relação ao método e à disposição da organização do conhecimento. $\mathrm{O}$ autor complementa que, em virtude dessas tentativas de classificações, no século XVI:

“[...] surgiu uma tendência a comprimir o conhecimento em esquemas, usualmente diagramas tipográficos, que ilustravam os ramos $e$ as bifurcações de disciplinas de acordo com o princípio da lógica ramista. Um impulso diagramático - uma tendência a mapear, delinear e 'especializar' segmentos do conhecimento.” (DARNTON, 1986, p. 250)

Entre os séculos XVI e XVII diversos outros estudiosos se dedicaram ao assunto. Knobloch (1989) cita, por exemplo, as obras seguintes: Enciclopaedia septem tomis distributa (1630), de Johann Heinrich Alsted (1588-1638), Ingenieurs schul (1637), de Johann Faulhaber (1580-1635), Cursus mathematicus (1644), de Pierre Hérigone (15801643), e Thesaurus mathematum (1646) Johann de Luneschlos. A esta lista, podemos acrescentar ainda Scholarum mathematicarum mibri unus et triginta (1569), de Petrus Ramus (1515-1572), e os prolegomenos do Euclidis elementorum libri XV (1574), de Christoph Clavius (1538-1612).

Outro ponto importante a ser considerado é que, ao longo da história, há aqueles que buscaram classificar os conhecimentos humanos em geral, tais como: São Tomás de Aquino (1225-1274), Guilherme de Ockham (1288-1347), Francis Bacon (1561-1626) e Ephraim Chambers (1680-1740); e outros que se preocuparam em examinar uma parte específica de uma determinada área do conhecimento. Neste artigo, temos como objetivo abordar a classificação das matemáticas de John Dee (1527-1608) e de Adriaan van Roomem (1561-1615), estudiosos que se dispuseram a esquematizar e sintetizar os conhecimentos além do âmbito do currículo baseado no quadrivium.

Ao compararmos as concepções daqueles que se ocuparam em organizar o conhecimento como um todo e daqueles que se debruçaram sobre uma ciência em particular - no caso, a matemática - em geral, podemos observar que há uma diferença no detalhamento das especificidades das matemáticas. Para exemplificar o primeiro caso, tomemos a classificação matemática do filósofo Francis Bacon (Figura 1), publicada em 1605 na obra The advancement of learnings. 


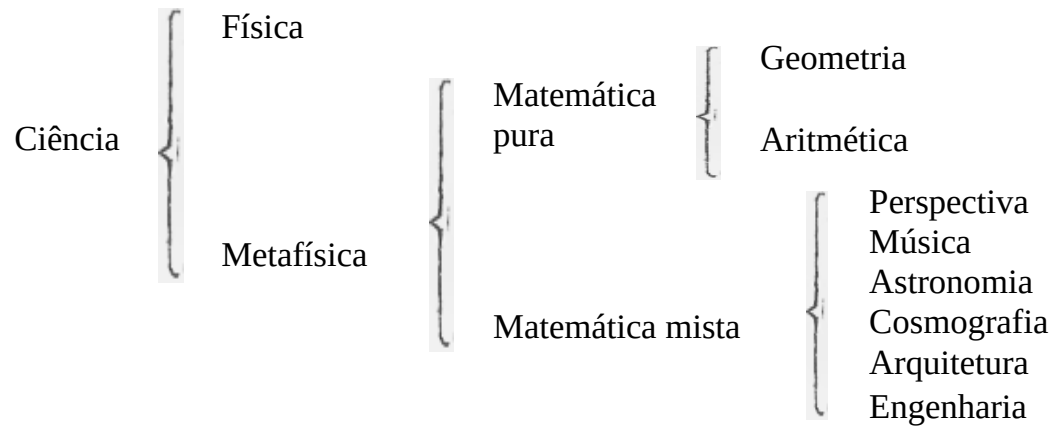

Figura 1. Parte da Árvore do Conhecimento de Francis Bacon.

Fonte: Adaptado de Darnton (1986).

Bacon formulou as Matemáticas no campo da Razão dos conhecimentos humanos (Filosofia), como parte da Filosofia Natural, dentro das Ciências Naturais e ramificada à Metafísica. As ciências matemáticas foram divididas em "pura" ou "mista"; sendo que a "matemática pura" abrangeu os tópicos de Geometria e Aritmética, enquanto que a "matemática mista" compreendeu temas relacionados com Perspectiva, Música, Astronomia, Cosmografia, Arquitetura e Engenharia. Bacon, porém, não explora em mais detalhes o campo das matemáticas e suas disciplinas.

Neste artigo, apresentamos duas classificações de estudiosos que se dedicaram exclusivamente às matemáticas. Na próxima seção, apresentamos uma tradução para o diagrama das matemáticas presente no prefácio escrito por Dee para a tradução inglesa dos Elementos de Euclides realizada por Henry Billingsley (1550-1606). Em seguida, apresentamos a tradução do segundo capítulo da obra Universae mathesis idea de van Roomen.

Certamente, estas classificações não podem ser generalizadas e entendidas como visão predominante nos séculos XVI e XVII. Este é um período de intensos debates científico e filosófico, e que gerou grande impacto no desenvolvimento de diversas áreas do conhecimento. No âmbito das matemáticas, é neste momento que ocorrem importantes discussões no que se refere à álgebra, ao cálculo diferencial e integral e à geometria análitica. Porém, ao apresentarmos as classificações de Dee e van Roomen, não estamos somente mostrando que estava presente no universo científico uma certa tradição matemática enraizada nos trabalhos da Antiguidade e do Medievo, mas também que essas mesmas tradições estavam sendo repensadas e reconfiguradas de forma a incorporar ideias contemporâneas.

Um de nossos intuitos é mostrar que o estudo das classificações matemáticas por meio de uma investigação histórica nos fornece elementos para a compreensão do processo de estruturação das matemáticas, bem como seus conceitos, visto que podemos verificar quais eram os conhecimentos e as bases teóricas presentes em cada uma dessas categorizações elaboradas em diferentes contextos e períodos. 


\section{John Dee e o prefácio aos Elementos de Euclides}

Filho de Johanna Wilde e Rowland Dee (1500-1553), que serviu à sociedade inglesa atuando como cavalheiro da corte do rei Henry VIII, John Dee obteve uma educação privilegiada, dado que, naquele período, praticamente apenas cidadãos pertencentes à nobreza tinham acesso aos estudos acadêmicos. Dee iniciou seus estudos na Chantry School, localizada em Chelmsford, e posteriormente, aos quinze anos, adentrou para o St. John's College, em Cambridge, tendo recebido o título de Bachelor of Arts (B.A.), em 1545, e Master of Arts (M.A.), em 1548. Na década de 1550, Dee viajou para Louvain e para Paris, tendo estudado com Gemma Frisius (1508-1555) e Gerard Mercator (15121594) (DE SMET, 1990).

Ao retornar para a Inglaterra, sob o reinado de Edward VI, Dee produziu algumas obras relacionadas à astronomia e um livro abordando a causa das marés. No entanto, após a ascensão da rainha Mary I, Dee foi acusado de uso de magia e traição, julgado pela Star Chamber e, por fim, condenado à prisão. Nada foi provado contra ele e, passado algum tempo, foi liberado, mas entregue à tutela do Bispo Edmund Bonner (1500-1569) por um breve período. Quando a rainha Elizabeth I assumiu o reinado da Inglaterra em 1558, houve uma calmaria a essa perseguição em relação a Dee, devido à sua proximidade com a rainha (SMITH, 1909).

Em 1558, Dee publicou seu trabalho intitulado Propaedeumata aphoristica de praestantioribus quibusdam naturae virtutibus (Introdução aforística sobre certas virtudes da natureza mais importantes), evidenciando seu conhecimento sobre filosofia natural e os contatos com matemáticos do período, dado que essa obra foi dedicada a Mercator, agradecendo pelos momentos de estudos em Louvain. De acordo com Almeida (2012), Girolamo Cardano (1501-1576), Orôncio Fineu (1495-1555), Frederico Commandino (1509-1575), Abraham Nortelius (1527-1598) e Gemma Frisius foram outros matemáticos com quem Dee manteve contato

Em 1570, Henry Billingsley publicou a obra The elements of geometrie of the most auncient Philosopher Euclide of Megara (Figura 2), uma tradução para a língua inglesa dos Elementos de Euclides e convidou John Dee para escrever seu prefácio (RAMPLING, 2012). Ao prefaciar, Dee afirma que a referida obra é direcionada para pessoas que não tem conhecimento de latim (unlatined people) e não para aqueles eruditos que estão nas universidades e são versados em latim.

"E onde fui solicitado, de certa forma, para aludir, por que, em nossa língua vulgar [comum], esta parte da Ciência Principal da Geometria, chamada de Elementos Geométricos de Euclides, é publicada para o seu trato: sendo [vocês] pessoas não latinizadas, e não eruditos universitários. Na verdade, eu acho [esta obra] desnecessária [para os eruditos latinizados]." (DEE, 1570, s/p, tradução nossa) ${ }^{1}$

\footnotetext{
${ }^{1}$ No original, "And where I was willed, somewhat to alledge, why, in our vulgare Speche, this part of the Principall Science of Geometrie, called Euclides Geometricall Elementes, is published, to your handlyng: being vnlatined people, and not Vniuersitie Scholers: Verily, I thinke it nedelesse.”
} 


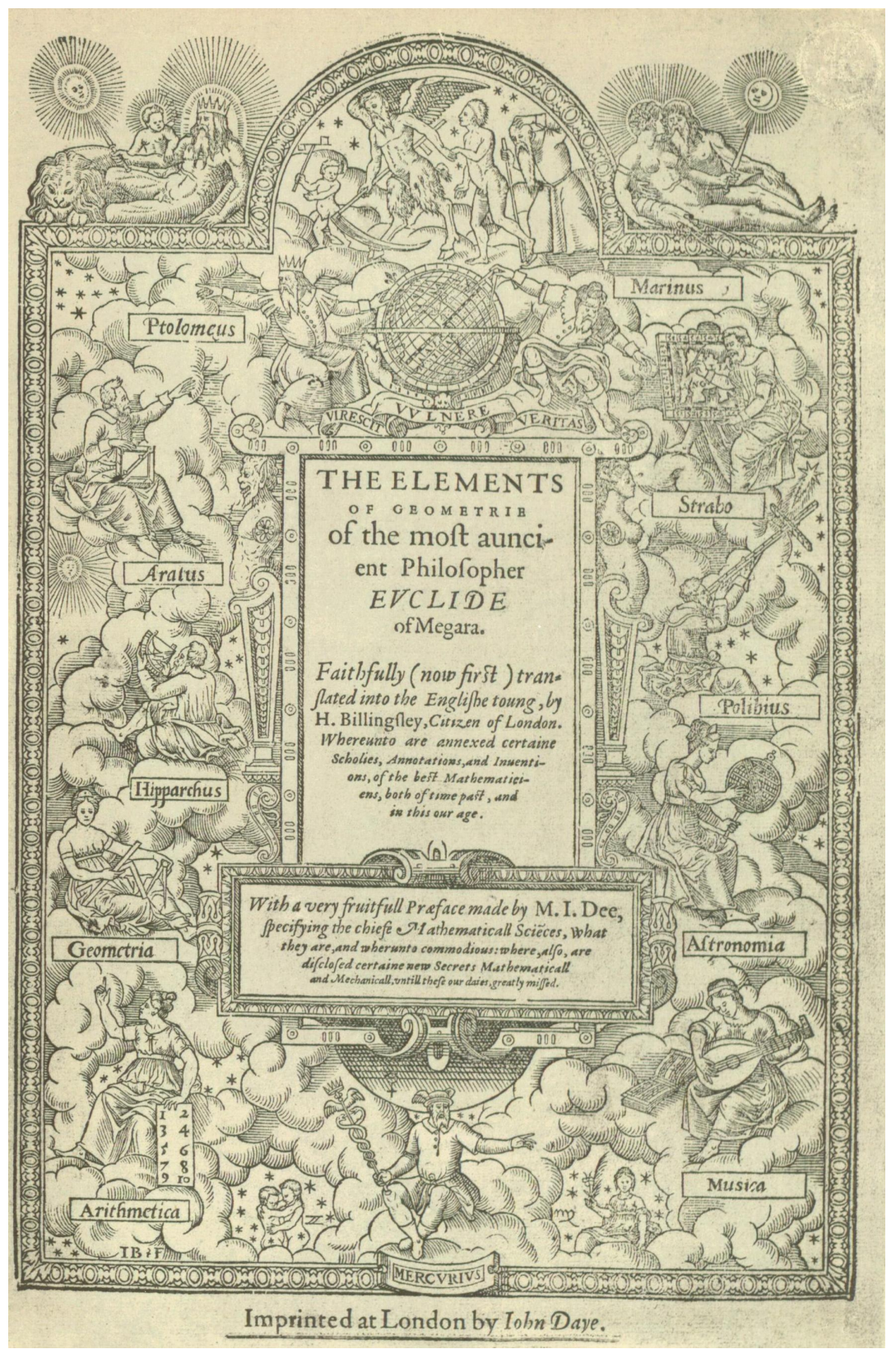

Figura 2. Frontispício da obra The elements de Billingsley. Fonte: Billingsley (1570). 
Dee, justificando a tradução inglesa dos Elementos, ressalta ainda que, naquele momento, muitas obras matemáticas escritas em grego e latim estão sendo traduzidas para as línguas vernáculas em diversas regiões da Europa. Entretanto, Rampling (2012) destaca que:

"No entanto, o volume em folio de Billingsley, com quase mil páginas e ricamente ilustrado com figuras, teria sido uma compra extravagante para todos, exceto para os praticantes mais abastados. O forte apelo à utilidade [das matemáticas] feito em todo o Prefácio, portanto, tem um sabor retórico, embora não precisemos duvidar da sinceridade do compromisso de Dee com o valor prático das matemáticas. Ao se dirigir a uma ampla gama de leitores possíveis, Dee chamou a atenção para o método experimental e o papel da matemática no estudo de fenômenos naturais e problemas cotidianos.” (RAMPLING, 2012, p. 138, tradução nossa $)^{2}$

O prefácio de Dee contém mais de cinquenta páginas com a intenção de especificar as principais Ciências Matemáticas (Mathematicall Sciences), apresentando na última página um diagrama (Groundplat) com essas ciências descritas no texto, também chamado pelo autor de Árvore Matemática (Mathematical Tree). De acordo com Dee, ninguém até a data de sua publicação teria conseguido descrever essas Artes Matemáticas (Mathematicall Artes) como ele apresenta no prefácio, tornando difícil que elas conquistassem o devido crédito.

Assim, o autor do prefácio estabelece uma série de Artes Matemáticas, definindo e explicando, brevemente, os seus principais propósitos. Para tanto, Dee (1570, s/p, tradução nossa), define Arte como sendo “[...] uma Doutrina Metódica completa, que tem abundância de matéria suficiente e peculiar para lidar [com os saberes da própria Arte], a partir da permissão do Filósofo Metafísico: o conhecimento do qual é necessário para o estado humano."3

\section{Tradução, notas e comentários ao diagrama das Matemáticas de Dee}

A seguir, apresentamos a tradução do diagrama contido na última página do Prefácio, em que Dee organiza as Artes que ele define em forma de Árvore Matemática, contendo as ciências principais e suas ramificações. Logo após, inserimos algumas notas explicativas a respeito da tradução de alguns termos e, por fim, comentários.

\footnotetext{
${ }^{2}$ No original, "Yet Billingsley's folio volume, almost a thousand pages long, and lavishly illustrated with figures, would have been an extravagant purchase for all but the most well-to-do practitioners. The strong appeal to utility made throughout the Praeface therefore has a rhetorical flavour, although we need not doubt the sincerity of Dee's commitment to the practical value of mathematics. In addressing a wide range of possible readers, Dee drew attention to experimental method, and the role of mathematics in studying both natural phenomena and everyday problems.”

${ }^{3}$ No original, "[...] a Methodicall cõplete Doctrine, hauing abundancy of sufficient, and peculiaer matter to deale with, by the allowance of the Metaphisicall Philosopher: the knowledge whereof, to humaine state is necessary."
} 


\section{J. DEE \\ Here haue you (according to my promisse) the Groundplat of my MATHEMATICALL Præface: annexed to Euclide (now first) published in our Englishe tounge. An. 1570. Febr. 3.}

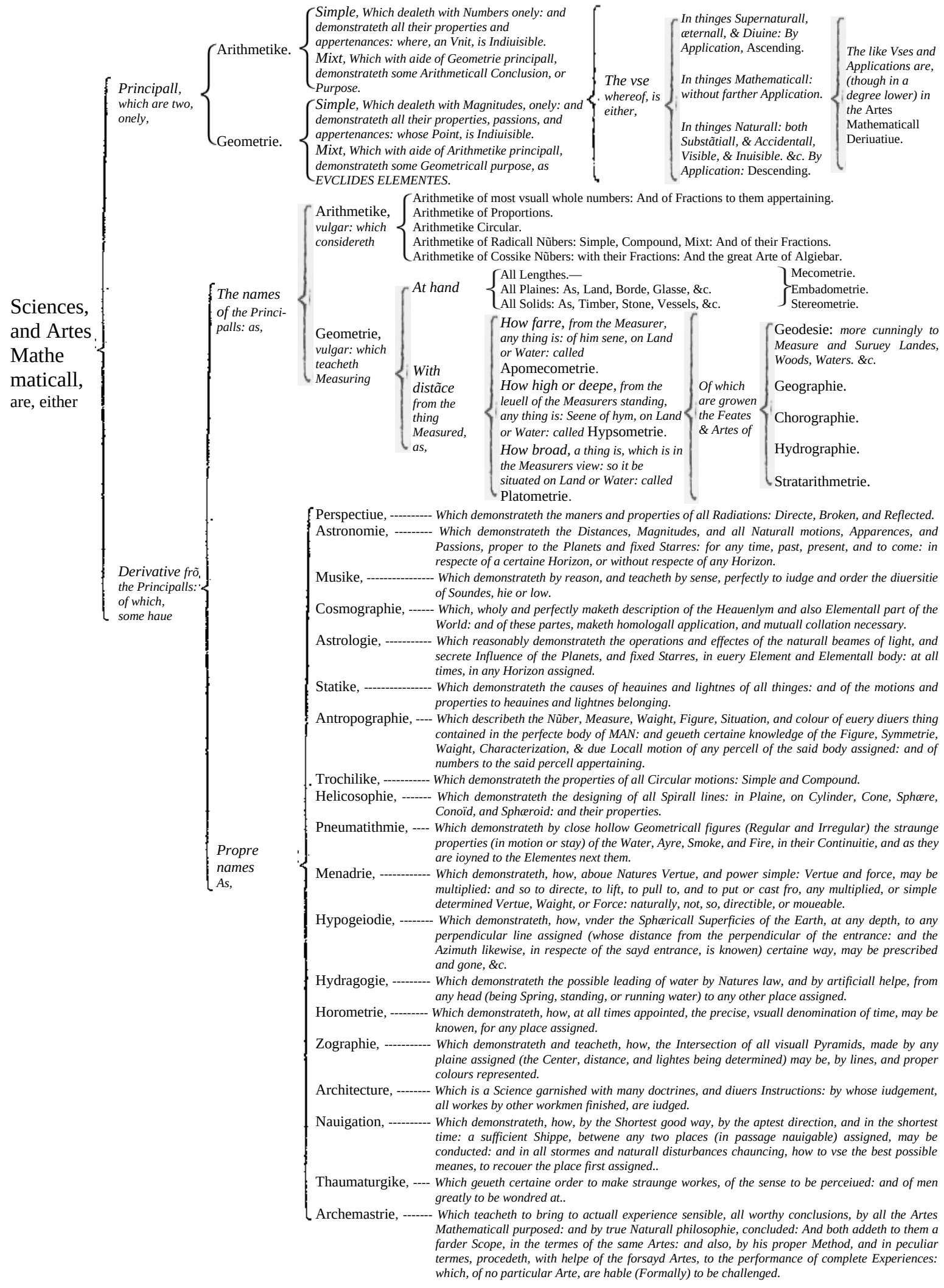



meu prefácio MATEMÁTICO: anexado a Euclides (agora o primeiro) publicado na nossa língua inglesa. 3 fev. do ano 1570.

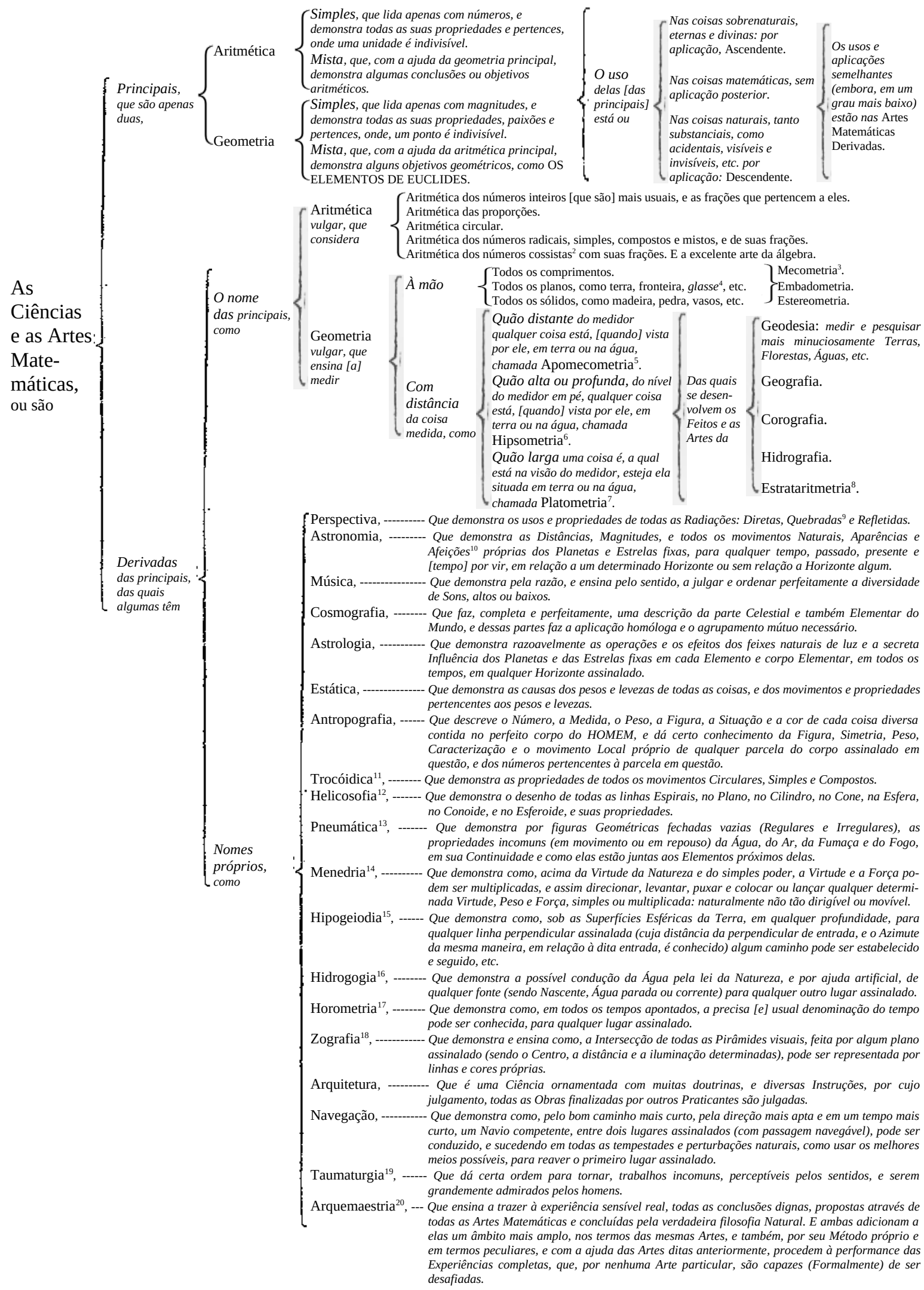


Notas:

${ }^{1}$ Não há uma tradução específica para o termo Groundplat, que foi utilizado por Dee (1570) para apresentar seu diagrama. No início do prefácio, o próprio Dee também se refere a ele como uma Árvore Matemática (Mathematicall Tree). Nesse sentido, alguns autores mantêm esse termo, inserindo aspas para referi-lo (vide RAMPLING 2012). Entretanto, ele foi utilizado também para mencionar plantas baixas de cidades, isto é, desenhos técnicos esquemáticos, como pode ser visto em The Groundplat of Kanton (vide HOLLAR 1669) e The Groundplat of King's Lyn (vide HARROD 1874).

${ }^{2}$ Segundo Manders (2005, p. 189), “A álgebra alemã do século XVI fornecia regras para manipular e resolver equações principalmente lineares e quadráticas, incluindo sistemas de equações lineares e exemplos de sua aplicação"4. Um dos trabalhos mais influentes foi a obra de Christoff Rudolff (1499-1545) intitulada Behend unnd Hübsch Rechnung durch die kunstreichen regeln Algebre so gemeincklich die Coss genent werden ou, em tradução livre, "Cálculo ágil e bonito por meio das regras engenhosas da álgebra [que] são comumente chamadas de coss", publicado em 1525. "Influenciados por al-Khowarizmi e escritores islâmicos posteriores que chamaram o desconhecido (isto é, a variável $x$ ) shai, árabe para 'coisa', os textos latinos usaram res e os em italiano usaram cosa ('coisa'). Na Itália, a álgebra ficou conhecida como l'arte della cosa, na Inglaterra como cossike arte, ou a regra do coss, e na Alemanha, die Coss" (GULLBERG, 1997, p. 299). Daí teria surgido o termo cossike numbers que, segundo Smith (1925), foi usado pelos ingleses renascentistas para se referir a uma quantidade desconhecida. Em português, o termo "cossista" faz referência justamente a esta álgebra que tem como base à palavra "coisa" para se referir ao que, atualmente, denominamos incógnita.

${ }^{3} \mathrm{O}$ termo mecometria também aparece, com o mesmo sentido atribuído por Dee, na obra Planiglobium coeleste ac terrestre escrita por Isaac Habrecht (1544-1622).

${ }^{4}$ Dee (1570) não explica o significado do termo glasse. Porém, em geometria, estaria relacionado a algo plano (sem espessura). Talvez ele esteja se referindo à forma.

${ }^{5} \mathrm{O}$ termo apomecometria é utilizado para se referir a "Arte de calcular ou medir a distância e avaliar a natureza de objetos afastados” (APOMECOMETRIA, 2021).

${ }^{6}$ Segundo o dicionário Infopedia, "A hipsometria consiste na determinação da altitude de pontos situados sobre um plano de referência que se baseia em medições diretas e relacionadas com um ponto de altitude conhecida. As técnicas utilizadas para calcular a hipsometria são: por nivelamento ou por processos trigonométricos, [...]; pelo método barométrico [...]” (HIPSOMETRIA, 2021).

${ }^{7}$ A tradução do termo foi baseada na origem etimológica da palavra grega $\pi \lambda \lambda^{\prime}$ tos, que significa largura, e $\mu$ ćtpov, que significa medida (BOGNOLO, 1839, p. 1185).

${ }^{8}$ Embora não encontramos uma palavra atual que remeta ao termo "estrataritmetria", no século XVIII, o Diccionario Castellano con las voces de ciencias y artes y sus correspondientes en las tres linguas francesca latina e italiana apresentava uma tradução para o espanhol que tinha o seguinte significado: "a arte de colocar os soldados em batalha" (ESTRATARITMETRIA, 1793, p. 283).

${ }^{9}$ Por radiação quebrada, Dee se refere ao que hoje entendemos como refração.

${ }^{4}$ No original, "Sixteenth-century German algebra provided rules for manipulating and solving primarily linear and quadratic equations, including systems of linear equations, and examples of their application”. 
${ }^{10}$ Afeição - palavra também mencionada na literatura como paixão, em latim, passio - é um termo aristotélico que designa o efeito sofrido por alguma substância a partir da ação realizada por outro agente (vide ARISTÓTELES 1995).

${ }^{11}$ Segundo Dee (1570), a trochilike também pode ser chamada de "Arte da Roda" (Whele Art), pois o seu resultado seria "vulgarmente recebido em rodas". A proposta de tradução do termo trochilike se baseou no conceito matemático de trocoide, que designa uma curva plana descrita por um ponto ligado a uma circunferência que gira de forma tangencial sobre uma reta fixa. Esta ideia nos remete ao que Dee considera como objeto de estudo desta Arte, ou seja, os movimentos circulares.

${ }^{12}$ Propomos esta tradução tendo em vista, os termos, em português, helicoidal e helicoide, e na palavra espanhola e francesa que designa a "arte de trazer figuras espirais em um plano" (TABOADA, s/d).

${ }^{13}$ Embora esta Arte seja denominada Pneumatithmie, Dee (1570) também afirma que ela é comumente chamada de Pneumática (Pneumatica, em latim).

${ }^{14}$ Propomos uma tradução para o português a partir do texto latino do diagrama de Dee elaborado por Alsted (1630). Além disso, é importante considerar que "Muitas das disciplinas de Dee - 'Embadometria', 'Zografia', 'Menedria' - são inteiramente obscuras, inéditas antes da publicação do 'Prefácio', e pouco mencionadas posteriormente [...]” (JARRETT, 2019, p. 13) .

${ }^{15}$ Ver nota 14.

${ }^{16}$ Propomos a tradução do termo semelhante à palavra espanhola que designa a arte de canalizar as águas, o que remete ao significado atribuido por Dee (1570).

${ }^{17}$ Dee (1570) diz ainda que esta disciplina foi chamada, pelos antigos, por Gnomônica (Gnomonice), e, mais recentemente, por Horologiografia (Horologiographia).

${ }^{18}$ Ver nota 14.

${ }^{19}$ A tradução do termo teve como base a palavra taumaturgia atual, embora os sentidos atribuídos possam ser considerados diferentes.

${ }^{20}$ A tradução do termo veio da palavra archemastery, do inglês atual.

Antes de abordar, especificamente, a classificação das artes matemáticas, Dee define o que seriam as Coisas Matemáticas (Mathematicall Things) e seu lugar referente a todas as coisas que existem. Segundo ele,

"Todas as coisas que existem, e têm existido, são encontradas em uma divisão tripla geral. Pois, ou elas são consideradas Sobrenaturais, Naturais ou de um terceiro ser. As coisas Sobrenaturais são imateriais, simples, indivisíveis, incorruptíveis e imutáveis. As coisas Naturais são materiais, compostas, divisíveis, corruptíveis e mutáveis. As Coisas Sobrenaturais são apenas compreendidas pela mente. Coisas Naturais podem ser entendidas pelo sentido exterior. Nas coisas Naturais,

\footnotetext{
${ }^{5}$ No original, “Many of Dee's subjects - 'Embadometrie', 'Zographie', 'Menadrie' - were entirely obscure, unheard of before the publication of the 'Preface', and little mentioned afterwards [...].”
}

RBHM, Vol. 21, nº 42, pp. 52-80, 2021 
probabilidade e conjectura têm lugar. Mas nas coisas Sobrenaturais, a demonstração principal e a mais segura Ciência devem ser tomadas. Pelas propriedades e comparações dessas duas, mais facilmente podem ser descritos o estado, a condição, a natureza e a propriedade daquelas coisas, que antes denominamos de um terceiro ser, que, por um nome peculiar, também são chamadas Coisas Matemáticas. Pois, estas, estando (de certa forma) no meio, entre as coisas sobrenaturais e naturais: não são tão absolutas e excelentes, como as coisas sobrenaturais, nem ainda tão básicas e grosseiras, como as coisas naturais: Mas são coisas imateriais: e não obstante, pelas coisas materiais são passíveis de serem um tanto significadas." (DEE, 1570, s/p, tradução nossa) ${ }^{6}$

Dee (1570) afirma ainda que as coisas matemáticas não podem apelar para probabilidades e conjecturas vagas, "mas apenas [para] uma perfeita demonstração, de verdades certas, necessárias e invencíveis: universalmente e necessariamente concluídas"7.

Entre as coisas matemáticas, duas são as principais: o número e a magnitude. Número é uma certa soma de unidades (vnits) e esta é considerada uma coisa matemática indivisível. Magnitudes são aquelas coisas matemáticas que podem ser classificadas como compridas (long), largas (broade) ou grossas (thicke), as quais são relacionadas, respectivamente, a linhas, superfícies e sólidos. Além disso, Dee salienta que número e magnitude não possuem qualquer materialidade, mas, como foi dito anteriormente, ganham sentido nas coisas naturais.

Segundo Rampling (2012, p. 139), a ideia de número presente no Prefácio de Dee, estando entre as coisas naturais e "divinas" - termo utilizado pela autora para se referir às coisas sobrenaturais -, "parece permitir uma intuição particular da Criação" ${ }^{\text {. Esta }}$ concepção provém de correntes neoplatônicas italianas. De fato, Dee cita Giovanni Pico della Mirandola (1463-1494) que "descreveu dois tipos de número: os 'números materiais' usados para contar (e, portanto, empregados para fins práticos) e 'números formais', que existiam como ideais platônicos, separados de todo o material ou considerações comerciais” (RAMPLING, 2012, p. 140).

\footnotetext{
${ }^{6}$ No original, "All thinges which are, \& haue beyng, are found vnder a triple diuersitie generall. For, either, they are demed Supernaturall, Naturall, or, of a third being. Thinges Supernaturall, are immateriall, simple, indiuisible, incorruptible, \& vnchangeable. Things Naturall, are materiall, compounded, diuisible, corruptible, and chaungeable. Thinges Supernaturall, are, of the minde onely, comprehended: Things Naturall, of the sense exterior, ar hable to be perceiued. In thinges Naturall, probabilitie and coniecture hath place: But in things Supernaturall, chief demõstration, \& most sure Science is to be had. By which properties \& comparasons of these two, more easily may be described, the state, condition, nature and property of those thinges, which, we before termed of a third being: which, by a peculier name also, are called Thynges Mathematicall. For, these, beyng (in a maner) middle, between thinges supernaturall and naturall: are not so absolute and excellent, as things supernatural: Nor yet so base and grosse, as things naturall: But are things immateriall: and neuerthelesse, by materiall things hable somewhat to be signified."

${ }^{7}$ No original, "But onely a perfect demonstration, of truthes certaine, necessary, and inuincible: vniuersally and necessaryly concluded:”

${ }^{8}$ No original, "[...] appear to permit special insight into the Creation.”

${ }^{9}$ No original, "[...] described two kinds of number: the 'material numbers' used for counting (and hence employed for practical purposes), and 'formal numbers', which existed as Platonic ideals, detached from all material or commercial considerations."
} 
São essas ideias que fundamentam a divisão do primeiro ramo das Ciências e das Artes Matemáticas (Sciences and Artes Mathematicall) em dois grupos. O primeiro é o das Artes Matemáticas Principais, que trata da Aritmética e da Geometria. Estas têm como objeto justamente os números e magnitudes, ditos "formais" por Rampling (2012). O segundo grupo é o das Matemáticas Derivadas, que aborda um conjunto de artes que são definidas a partir das Principais. Esse segundo grupo é subdividido em duas partes: aquelas ciências cujos nomes derivam das Principais - onde estão a Aritmética e a Geometria Vulgar, que estudam os números e magnitudes "materiais" (RAMPLING, 2012) - e aquelas artes que possuem nomes próprios.

Em relação às Matemáticas Principais, cada uma é dividida entre simples e mista. A Aritmética Simples lida com os números e suas propriedades, e a Geometria Simples trata das magnitudes e suas propriedades, conforme as definições descritas anteriormente. Já a Aritmética Mista faz suas demonstrações com o auxílio da Geometria e, da mesma forma, a Geometria Mista faz suas demonstrações com o apoio da Aritmética. Em seu diagrama, Dee afirma, ainda, que essas matemáticas principais podem ser utilizadas nas coisas Sobrenaturais, Matemáticas e Naturais, ou seja, em todas as coisas que existem e têm existido, conforme supracitado.

Em relação às Artes Derivadas, Dee (1570, s/p) afirma que elas, “[...] pelo Método Demonstrativo Matemático, ordenam e confirmam sua doutrina em Números ou em Magnitudes, tanto e tão perfeitamente, quanto o assunto em questão admitirá”. ${ }^{10}$ Assim, no tocante às Artes Matemáticas Derivadas, cujos nomes decorrem das ciências principais, estão a Aritmética Vulgar e a Geometria Vulgar. O termo vulgar é empregado pelo autor para se referir àqueles usos cotidianos e aplicações práticas destas Artes Matemáticas (RAMPLING, 2012).

Nesse sentido, a Aritmética Vulgar inclui os cálculos com números inteiros e suas frações, o estudo das proporções, os números radicais e suas frações, a aritmética circular que, segundo Dee (1570), é comumente chamada de "Aritmética das Frações Físicas e Astronômicas" e estuda os sexagesimais - e os números cossistas (cossike numbers) da "Arte da Álgebra".

A Geometria Vulgar é entendida de duas formas: uma em que os objetos e coisas medidas estão à mão, ou seja, estão junto a quem está medindo; e outra em que as coisas a serem medidas não estão ao alcance do medidor. No primeiro caso, Dee classifica a Geometria Vulgar em três artes: Mecometria, Embadometria e Estereometria. No segundo caso, são mencionadas também outras três artes: Apomecometria, Hipsometria e Platometria. A partir destas últimas, segundo o autor, se desenvolvem outras cinco Artes Matemáticas: a Geodesia, a Geografia, a Corografia, a Hidrografia e a Estrataritmetria.

A Geodesia, segundo o autor, é a arte de medir de forma precisa as dimensões de partes da Terra, sejam elas partes sólidas ou espaços cobertos pela água, como os rios e oceanos. Por outro lado, a Geografia tem como objetivo informar a localização de lugares específicos sobre a superfície da Terra, como cidades, montanhas, rios, etc. Já a Corografia, embora sua prática seja bastante diversa, Dee afirma que ela pode ser considerada uma parte da Geografia, tendo o intuito de descrever uma pequena parte de terra e seus

${ }^{10}$ No original, "[...] by Mathematicall demonstratiue Method, in Nũbers, or Magnitudes, ordreth and confirmeth his doctrine, as much \& as perfectly, as the matter subiect will admit.”

RBHM, Vol. 21, n 42, pp. 52-80, 2021 
pertences, sem considerar as medidas que ela tem com o todo. A Hidrografia fornece informações sobre os oceanos, localização das ilhas e os pontos principais em relação à costa marítima. A última das Artes Matemáticas que Dee relaciona com a Geometria Vulgar é a Estrataritmetria. Diferentemente das quatro anteriores - que abordam, de alguma forma, a medição e a localização de lugares na superfície terrestre - esta arte trata das habilidades geométricas no que concerne a atividade bélica.

A parte mais longa do diagrama de Dee - e que não exploraremos aqui - é aquela dedicada às "outras (muitíssimas) Artes Metódicas, que derivam da pureza, simplicidade e imaterialidade, de nossa Ciência Principal das Magnitudes” (DEE, 1570); elas, porém, têm nomes próprios, totalizando dezenove Artes Matemáticas, que são explicadas brevemente no próprio diagrama. São elas: Perspectiva, Astronomia, Música, Cosmografia, Astrologia, Estática, Antropografia, Trocóidica, Helicosofia, Pneumática, Menedria, Hipogeiodia, Hidrogogia, Horometria, Zografia, Arquitetura, Navegação, Taumaturgia e Arquemaestria.

\section{Adriaan van Roomen e as Matemáticas}

Adriaan van Roomen nasceu em 1561, em Louvain, e faleceu em Mainz, em 1615. Estudou matemática e filosofia no Colégio Jesuíta de Colônia e, nesta cidade, iniciou seus estudos em medicina, aos quais deu continuidade na Universidade de Louvain e se aperfeiçoou em Bolonha, onde recebeu o título de doutor em 1594. No que diz respeito ao ensino, é nesta área que ele atuou a maior parte de sua vida, tendo sido docente em Louvain e Würzburg. Entre 1586 e 1592, van Roomen também ensinou matemática na Universidade de Louvain. Embora a produção do autor seja diversificada, a maior parte são teses de seus alunos em Medicina. Contudo, também deixou contribuições para a matemática, tendo publicado trabalhos sobre questões relacionadas à geometria e à trigonometria (BOCKSTAELE, 1966; BOSMANS, 1907; RULAND, 1867; GONÇALVES; OLIVEIRA, 2010). Sua interação com diversos estudiosos daquele momento, através de correspondência e de visitas pessoais, atesta como ele esteve intensamente envolvido com as práticas matemáticas daquele período (GONÇALVES; OLIVEIRA, 2007; OLIVEIRA; HADDAD, 2018).

Van Roomen também publicou duas obras nas quais expôs sua visão sobre a classificação das disciplinas matemáticas. A primeira delas, intitulada Universae mathesis idea, foi publicada em 1602 em Würzburg e, três anos depois, em 1605, veio ao lume a obra Mathesis polemica em Frankfurt.

Para apresentar algumas das características essenciais do pensamento de van Roomen sobre a classificação das matemáticas, neste artigo, apresentaremos uma tradução do segundo capítulo da obra Universae mathesis idea ou "Ideia de todo o conhecimento". O título completo do referido trabalho é Universae mathesis idea qua mathematicae universim sumptae natura, praestantia, usus et distributio brevissime proponuntur e, em português, pode ser traduzido como "Ideia de todo o conhecimento através do qual são propostas a natureza, a excelência e a distribuição da matemática tomada do geral”. 
“Sobre a divisão das Matemáticas”, de van Roomen: tradução, notas e comentários

Segue a tradução do segundo capítulo da Universae mathesis idea. Em seguida apresentamos notas e comentários à tradução.

[p. 14]

\author{
DE MATHEMATI- \\ cæ divisione. \\ CAPVT II.
}

MATHEmaticarum censu comprehenduntur, tum eæ quæ verè Mathematicæ sunt, tum quæ quasi Mathematicæ dici possunt.

MATHEMATICA vera est tum Princeps sive primaria, tum ministrans sive Mechanica.

Mathematica princeps est qvæ soli qvantitatum speculationi intenta est; talis duplex est pura \& impura sive mixta. [p. 14]

\author{
CAPÍTULO 2.
}

Sobre a divisão das MATEMÁTIcas.

Pelo censo das MATEmáticas são compreendidas tanto aquelas que são verdadeiramente Matemáticas, quanto aquelas que podem ser ditas como que matemáticas.

A MATEMÁTICA verdadeira é tanto a Principal ou primária, quanto a que serve ou Mecânica.

A matemática principal é aquela que está segura da simples especulação da quantidade; ela é dupla, pura e impura, ou seja, mista.

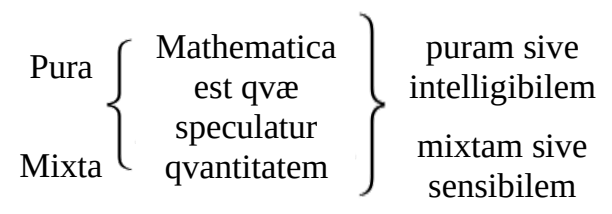

Pura iterum duplex universalis \& specialis.

Vniversalis est qvæ circa omnem versatur qvantitatem nempe Logistice \& prima Mathesis, illa ut organum scientiæ, hæc ut scientia.

[p. 15] Specialis qvoqve duplex est Arithmetica \& Geometria sub qva \& Stereometria.

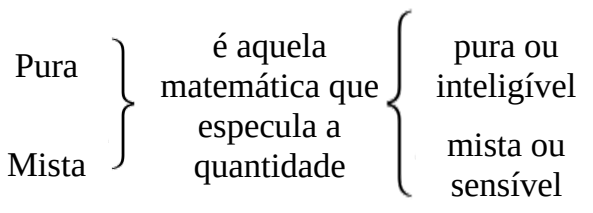

A [matemática] pura é novamente dupla, universal e especial.

A [matemática] universal é aquela que versa sobre toda quantidade, certamente a Logística e o Conhecimento primeiro ${ }^{1}$, a primeira como instrumento da ciência e a última como ciência.

[p. 15] A [matemática] especial também é dupla, Aritmética e Geometria, sob a qual está a Estereometria. 
Mixtæ objectum qvantum est, idqve vel æternum vel corruptibile.

Aeternum sive incorruptibile mundus est, ejusqve partes integrantes, de qvibus Cosmographia, Ouranographia, Geographia, Astronomia \& Chronologia.

Corruptibilia objecta sunt substantia de qvibus Geodesia, Optica, Euthymetria \& Musica.

Mechanica Mathesis est qvæ qvantitatum speculationi, adjungit opus sive factionem Machinarum.

Mechanica duplex est ratione finis ipsarum Machinarum qvi vel est usus vel actio sive motus activus: Neutra harum nomen sibi invenit proprium.

Mechanica efficiens organa usus gratiâ (siue is usus sit sum qviere sive cum motu passivo conjunctus) multiplex esse potest, præcipuus tamen est observatio, circa qvam versatur Sphceropoeia sive Sphæropoëtica.

Qvæ verò machinas efficit actionis gratia definiri potest ars ad ea qvæ vires hu-[p. 16] manas superant trahendum, impellendum, ferendum, machinarum fabricatrix.

Vel est ars cogendi corpora qvantum fieri potest vt contra nutum ferantur.

Mechanica hæc actionem spectans duplex est, universalis sive Elementaris \& particularis.
O objeto das [matemáticas] mistas é aquilo que pode ser quantificado, e ele é ou eterno ou corruptível.

Eterno ou incorruptível é o mundo e suas partes integrantes, sobre as quais [versam] a Cosmografia, a Uranografia, a Geografia, a Astronomia e a Cronologia.

Os objetos corruptíveis são as substancias, sobre as quais [tratam] a Geodesia, a Óptica, a Eutimetria ${ }^{2}$ e a Música.

O Conhecimento Mecânico é aquele que, com a especulação das quantidades, apoia a obra ou o fazer das Máquinas.

A Mecânica é dupla pela razão da finalidade das próprias Máquinas, que ou é o uso, ou a ação, ou o movimento ativo: o nome de nenhuma delas provém de si própria.

A Mecânica eficiente pode ser múltipla, graças ao uso do instrumento (ou esse uso se faz calmamente ou conjuntamente com o movimento passivo). A observação ainda é a principal, sobre a qual versa a Sphaeropoeia ou Sphaeropoetica ${ }^{3}$.

A arte fabricadora das máquinas pode ser definida pela graça da ação que faz as máquinas as quais superam as forças [p. 16] humanas da ação que deve ser trazida, impelida, carregada.

Ou é a arte de juntar os corpos, tanto quanto pode ser feito para que carreguem contra o comando.

A Mecânica que observa esta ação é dupla: universal ou Elementar, e particular. 
Vniversalis continet elementa motus violenti; diciturqve propriè Mechanica, Pappo Manganaria.

Particularis est qvae certo \& definito applicatur motori, qvi esse potest externus vel internus.

Externum motorem vocamus qvi extra organum existit, circa qvem inanimum Mechanopoetica, vel animatum Organopoetica versatur.

Internum dicimus qvi intra organum includitur, qualia vocamus automata, de qvibus Automatopoetica.

Quasi mathematicæ plures sunt, inter qvas tamen principem locum obtinent Architectura \& Ars militaris.
A [mecânica] universal contém os elementos do movimento violento e é dita propriamente Mecânica, ou [como diz] Pappus, Manganaria ${ }^{4}$.

A [mecânica] particular é aquela que é aplicada a um motor certo e definido, que pode ser externo ou interno.

Chamamos motor externo o que existe fora do instrumento: a Mechanopoetica ${ }^{5}$ versa sobre o que é inanimado, ou a Organopoetica $^{6}$ [que versa] sobre o animado.

Dizemos interno o que está incluído dentro do instrumento, o qual chamamos automático, sobre o qual trata a Automatopoetica ${ }^{7}$.

As como que matemáticas são muitas, entre as quais obtêm o primeiro lugar a Arquitetura e as Artes militares.

Notas:

${ }^{1}$ A disciplina denominada prima mathesis é também chamada por van Roomen - e por outros autores do período - como mathesis universalis. Em alguns casos, o termo mathesis não é traduzido pela literatura (PALKOSKA, 2017; SASAKI, 2004), em outros, atribuí-se o sentido de "matemática” (RABOUIN, 2005; 2009; WEBER, 1964). Porém, aqui propomos uma tradução para o português como "conhecimento”, outra possibilidade de sentido para esta palavra. Esta adoção se dá devido ao fato de que. no capítulo traduzido, van Roomen faz uma distinção entre as palavras mathematica e mathesis. $\mathrm{O}$ autor atribui claramente o uso de mathematica para o conjunto das primeiras disciplinas, as matemáticas principais, que são compostas pelas matemáticas puras e mistas, ou seja, aquelas que buscam somente a especulação das quantidades. Por outro lado, ao abordar as disciplinas mecânicas, o termo usado passa a ser mathesis, o que nos leva a considerar que o autor provavelmente estava se referindo a uma forma de conhecimento mais geral.

${ }^{2}$ Eutimetria é a parte da geometria que trata das linhas.

3 Este termo não será traduzido para o português pois, além de não ter uma palavra equivalente atualmente, sua origem etimológica leva a um significado diferente do atribuído pelo autor, conforme comentaremos posteriormente. Convém salientar ainda que, tanto em Dee, como em van Roomen, a criação de termos "atesta uma mentalidade comum 
do matemático do século XVI, voltada para a inovação, exploração e a criação de novas disciplinas, de vanguarda, embora um tanto esotéricas” (JARRETT, 2019, p. 13) ${ }^{11}$.

${ }^{4}$ Aqui a palavra não foi traduzida, mas convém salientar que "[...] autores de tratados de mecânica do final do século XVI empregam o termo manganaria para descrever um artifício mecânico" (WOLFE, 2004, p. 4) ${ }^{12}$.

${ }^{5}$ Ver nota 3.

${ }^{6}$ Ver nota 3.

${ }^{7}$ Ver nota 3.

A concepção de van Roomen está baseada em diversos conceitos, principalmente ideias aristotélicas. Em sua visão, “a ciência matemática em geral é [parte] das especulativas, pois a finalidade da matemática não é uma ação ou um modo de fazer, mas a especulação de qualquer que seja a quantidade” (VAN ROOMEN, 1602, p. 7) ${ }^{13}$. Sendo assim, para van Roomen, como também para Aristóteles, as disciplinas matemáticas não são ciências práticas (ou seja, aquelas que investigam a ação humana nas suas diferentes formas), nem produtivas (aquelas que se dedicam ao estudo dos trabalhos feitos pela inteligência humana com materiais pré-existentes) (SAITO, 2015). Nesta concepção, o pensar, foco das ciências especulativas, é tido como gerador de uma forma de conhecimento superior e, nesta categoria, estão a metafísica, a física e as matemáticas. Embora, as matemáticas sejam consideradas importantes, elas estão em um lugar intermediário entre as especulativas.

As disciplinas matemáticas teriam como objeto de estudo, nas palavras de van Roomen (1602, p. 7), "qualquer coisa contínua ou discreta, como dos corpos do mundo, dos movimentos, dos pesos, dos sons, dos raios visuais, dos campos, dos vasos, etc." ${ }^{14}$. Vemos aqui que, na concepção do autor, as matemáticas buscam uma compreensão não somente dos números e das formas geométricas, mas também de tudo aquilo que seja passível de ser quantificado.

Inicialmente, a classificação está dividida em dois grupos: as matemáticas, "ditas verdadeiramente matemáticas", e as "como que matemáticas" (VAN ROOMEN, 1602, p. 14). Entre as matemáticas verdadeiras, o autor continua sua classificação dividindo-as em outros dois grupos: as matemáticas principais e as mecânicas.

Em primeiro lugar, é importante notar aqui que a criação de um grupo para as disciplinas "como que matemáticas” mostra uma visão ampliada de van Roomen diante do conceito de quantidade, compreendendo que esta ideia poderia incorporar às matemáticas disciplinas que até então não eram incluídas como parte delas. $\mathrm{O}$ autor considera que

\footnotetext{
${ }^{11}$ No original, “[...] testifies to a common mentality of the sixteenth-century mathematician, directed towards innovation, exploration and the forging of novel, cutting-edge, if somewhat esoteric, disciplines.”

${ }^{12}$ No original, "[... late sixteenth-century authors of treatises on mechanics employ the term manganaria to describe mechanical artífice.”

${ }^{13}$ No original, "Mathematicae scientiae in genere est speculativarum. Finis manque Mathematicae non est actio vel factio, sed speculatio qantitatum quarumcunque [...]”.

${ }^{14}$ No original, “[...] quarumcumque rerum continuarum vel discretarum, vt corporum mundanorum, motuum, ponderum, sonorum, radiorum cisualium, agrorum, vasorum, etc.”.
} 
"existem também algumas [disciplinas] que possuem conhecimentos afins, que não são compreendidas pelo censo das matemáticas, porém não corretamente" 15 (VAN ROOMEN, 1602, pp. 100-101) e essas são denominadas por ele de "como que matemáticas”. Por outro lado, é interessante notar que as mecânicas - já aceitas entre os matemáticos e inseridas no conjunto das matemáticas de van Roomen - não tratam propriamente das quantidades, e o próprio autor afirma que, "daí, a mecânica também não pode ser considerada matemática, embora costume ser aceita entre as matemáticas”16 (VAN ROOMEN, 1602, p. 7).

As matemáticas principais são subdivididas em outros dois grupos: as puras e as mistas, também denominadas impuras. Enquanto a primeira estuda as coisas inteligíveis, a segunda considera as coisas sensíveis. Sales (2017) pondera que os estudos de Platão foram organizados baseando-se no mundo abstrato das ideias, enquanto que Aristóteles se ocupou em descrever os conhecimentos no mundo sensível das coisas concretas. Desse modo, a dualidade inteligível-sensível apresentada por van Roomen remete à concepção aristotélica que diz que as coisas inteligíveis são aquelas que se produzem no intelecto, enquanto as coisas sensíveis são aquelas percebidas pelos nossos sentidos.

Na classificação de van Roomen, são quatro as matemáticas puras: logística ou computação (supputatrix), conhecimento primeiro (prima mathesis) ou conhecimento universal (mathesis universalis), aritmética e geometria. As duas primeiras são denominadas matemáticas puras universais e as outras duas matemáticas puras especiais.

Segundo van Roomen, a logística ou computação "é aquela que, com o benefício dos cânones universais, obtém o desconhecido a partir de números dados em condições adequadas. Poderia, não incomodamente, se a expressão fosse aceita, ser chamada aritmopraxia” (VAN ROOMEN, 1602, p. 17) ${ }^{17}$. A logística não busca as propriedades dos números, nem se baseia em teoremas aritméticos, mas tem como objetivo entender como numerável o objeto de estudo das outras matemáticas. Segundo Sasaki (2004, p. 352, tradução nossa), ela é "inteiramente geral e requer pouco conhecimento preliminar".

Já o primeiro conhecimento ou conhecimento universal busca apresentar princípios universais a todas as disciplinas matemáticas. Na visão do autor, esta disciplina precederia todas as matemáticas, tanto puras, como mistas, ocupando o primeiro lugar entre elas.

As matemáticas puras especiais são mais conhecidas historicamente. A aritmética é a disciplina que estuda os números e suas propriedades, e a geometria é a ciência da mensuração e estuda as três magnitudes geométricas: linhas, superfícies e corpos, sendo o ponto o princípio de tais grandezas.

As matemáticas mistas também são subdivididas em dois grupos, de acordo com a corruptibilidade do objeto de estudo destas disciplinas. Na concepção aristotélica, a geração e a corrupção são níveis de transformação que ocorrem nos quatro elementos presentes nos sublunares, a saber, terra, água, fogo e ar, e tratam da passagem do "não ser” para o "ser" e

15 No original, “[...] sunt \& aliae ita Mathesi affines sunt, ut à nonnullis sub Mathematicarum censu comprehendantur, verùm non rectè".

${ }^{16}$ No original, "Vnde etiam Mechanica propriè non potest esse Mathematica, licet inter Mathematicas soleat recipi”.

${ }^{17}$ No original, "[...] est quae beneficio canonum universalium, ex datis numeris rebus accommodatis quaesitum elicit. Posset non incommodè si vox recepta esset Arithmopraxia vocari [...].” Propomos uma tradução para o

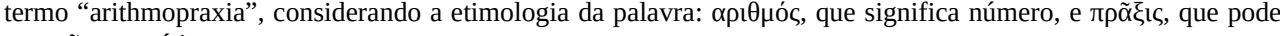
ser ação ou prática.

RBHM, Vol. 21, nº 42, pp. 52-80, 2021 
do "ser” para o "não ser”, respectivamente. É importante notar que esta concepção estava inserida em um sistema de mundo geocêntrico, seguindo a estrutura ptolomaica. Nesta perspectiva, a Terra ocupa o centro do sistema de mundo e depois vem um conjunto de esferas concêntricas nas quais estão os demais planetas e as estrelas. O primeiro dos planetas é a Lua, que ocupa a primeira esfera logo acima da Terra. Em seguida - embora tenha sido motivo de controvérsias - vem Mercúrio, Vênus, Sol, Marte, Júpiter, Saturno e a esfera das estrelas fixas. Todas as coisas localizadas abaixo da esfera da Lua são formadas, então, pelos quatro elementos, que são corruptíveis. Por outro lado, os planetas, as estrelas e tudo que há na esfera da Lua e acima dela são incorruptíveis, pois são feitos de um quinto elemento eterno e que não sofre mudanças (OLIVEIRA, 2015; VAN ROOMEN, 1591).

Entre as disciplinas matemáticas mistas, que estudam os objetos incorruptíveis, van Roomen menciona a Cosmografia, a Uranografia, a Geografia, a Astronomia e a Cronologia. Contudo, quando lemos a obra completa, o número de disciplinas deste grupo aumenta consideravelmente.

Embora o autor indique, no segundo capítulo de sua obra, que a astronomia e uranografia como estando em um mesmo "patamar", ao ler o capítulo específico a respeito dessas disciplinas, van Roomen coloca a uranografia como uma de suas partes, indicando, inclusive, ser a principal. Nas suas palavras:

"A astronomia é a ciência do movimento dos corpos celestes. A uranografia distingue o céu em suas partes tanto sensíveis, quanto inteligíveis. Sensíveis são as estrelas e a via láctea, mas inteligíveis são as esferas e os círculos. E novamente a uranografia é parte da astronomia e, certamente, a primeira." (VAN ROOMEN, 1602, p. 26$)^{18}$

Já “a cronologia ou cronometria é a ciência que explica a dimensão e a distinção do tempo através do movimento dos astros" (VAN ROOMEN, 1605, p. 33) ${ }^{19}$.

Ainda segundo o autor, a astrologia ou astromancia estuda as propriedades e as configurações dos corpos celestes que geram mutações nas coisas presentes nos sublunares. É interessante notar aqui que o autor considera a astrologia "filha de duas ciências" (VAN ROOMEN, 1602, p. 47) ${ }^{20}$ : a astronomia e a física.

No capítulo sobre a cosmografia e a geografia, van Roomen apresenta, na verdade um conjunto de disciplinas afins. A cosmografia é considerada por ele a disciplina que estuda as partes terrestres segundo sua latitude e longitude, fazendo uma comparação entre as partes da Terra e as partes do céu. A geografia mostra a localização de um lugar em relação aos limites visíveis na Terra. A hidrografia descreve os mares, as costas maritmas e os caminhos navegáveis que são encontrados em toda a Terra. A topografia faz uma descrição minuciosa de algum lugar particular ou explicando algum aspecto histórico da

${ }^{18}$ No original, "Astronomia scientia est motus corporum caelestium. Ouranographia coelum in suas partes distinguit tum sensibiles, tum intelligibiles. Sensibiles sunt stellae \& via láctea, intelligibiles verò sp[h]aerae \& circuli. Est porrò Ouranographia pars Astronomiae, \& quidem prima.”

${ }^{19}$ No original, "Chronologia siue Chronometria est scientia explicans temporis dimensionem \& distictionem, per motum astrorum."

${ }^{20}$ No original, “[...] duarum scientiarum filia [...]”. 
constituição do referido local. Já a corografia exprime, numa figura de pequena escala, os lugares separados do restante. "O corógrafo, portanto, exibe todas as coisas que são descritas ou propostas pelo topógrafo com os olhos" 21 . A topotesia (topothesis), ciência própria dos poetas, faz a descrição de alguns lugares não existentes, como se existissem, narrando ou através de uma pintura. A anemografia é a ciência que descreve os ventos e os instrumentos de observação dos ventos. Por fim, outra disciplina é a limineurética ${ }^{22}$, que informa a localização dos portos de acordo com a longitude, latitude e da declinação magnética.

As disciplinas que estudam os objetos corruptíveis são as seguintes: geodesia, óptica, eutimetria e música. A geodesia diz respeito ao estudo das medidas de partes da terra. A óptica, também denominada pelo autor de perspectiva, "é a ciência que explica as propriedades dos raios da visão" (VAN ROOMEN, 1602, p. 55) "23. "A eutimetria é a ciência que mede linhas retas finitas pelos raios visuais convenientemente diretos" (VAN ROOMEN, 1602, p. 56) ${ }^{24}$. Por fim, a música é a disciplina que estuda as razões entre os sons.

Além disso, as mecânicas apresentam um conjunto de cinco disciplinas que tratam da produção e da ação de instrumentos e máquinas. Os nomes são inventados e suas definições, provavelmente, se remetem à concepções próprias do autor. Uma delas é a sphaeropoeia ou sphaeropaeia. Tal nome parece ter alguma relação com os termos sphaera (esfera) e poiesis (criação ou produção), daí sphaeropoeia significaria "produção de esferas", porém van Roomen utilizou o termo com outro sentido: “A sphaeropaeia é a arte mecânica que ensina a construir instrumentos aptos para a observação e mensuração" (VAN ROOMEN, 1605, p. 59) ${ }^{25}$. Outra das disciplinas mecânicas é a manganaria ou maquinária (mechanaria), que na visão do autor, "é a arte dos grandes pesos que devem ser movidos" (VAN ROOMEN, 1602, p. 64) ${ }^{26}$. "A mechanopoetica é a arte de fazer máquinas que para se moverem requerem um motor externo inanimado" (VAN ROOMEN, 1602, p. 78) ${ }^{27}$, ou seja, para que tais máquinas executem seus movimentos, elas dependem da ação de um agente externo. Aparecem ainda a arte de confeccionar instrumentos bélicos, denominada organopoetica, e a thaumatopoetica que é a arte que produz instrumentos que se movem por si próprios, sem a necessidade de motor externo.

Após esta breve descrição da classificação das disciplinas matemática de van Roomen, torna-se importante ressaltar que alguns autores (KAWAJIRI, 1979; BROWN, 1991) atribuem a origem do termo "Mixed Mathematics" (Matemática Mista) a Francis Bacon, por meio de sua obra de 1605 intitulada The advancement of learnings. No entanto, pudemos observar que, em 1602, ao apresentar sua classificação das matemáticas, no segundo capítulo da Universae mathesis idea, van Roomen fez uso da expressão

\footnotetext{
${ }^{21}$ No original, "Chorographus ergo omnia ea oculis exhibet, quae à Topographo describuntur siue proponuntur.”

${ }^{22}$ Aqui, propomos uma tradução para "limineuretice”.

${ }^{23}$ No original, “[...] est scientia proprietates radiorum visuorum explicans.”

${ }^{24}$ No original, "Evthymetria est scientia quae per rádios visuales aptè directos, líneas rectas finitas metitur”.

${ }^{25}$ No original, "Sphaeropaeia est Mechanica ars docens construere instrumenta observationis \& dimensionibus apta."

${ }^{26}$ No original, “[...] est ars movendorum magnorum ponderum.”

${ }^{27}$ No original, "Mechanopoëtica est ars faciendi machinas, quae ut moveatur motorem requiruntur externum inanimatum.”
} 
“matemática mista”. Como vimos anteriormente, Dee também fez uso do termo “mista”, no entanto, Bennett (2013) relata que, nesse caso, a palavra em nada tem a ver com o que os historiadores chamam de "matemática mista”, dado que Dee considera a expressão "mista" somente em virtude da "mistura” entre conceitos aritméticos e geométricos utilizados na demonstração de resultados matemáticos, ou seja, uma aplicação entre os próprios elementos da "matemática pura”, sem aspectos das ciências que abordam tópicos de ordem física. Posto isto, não temos elementos suficientes para afirmar que van Roomen tenha sido o primeiro a fazer uso do termo "matemática mista”, mas certamente podemos concluir, diferentemente de Kawajiri (1979) e Brown (1991), que Bacon, em 1605, não foi o criador da expressão.

Ambos os estudiosos - van Roomen e Bacon - consideram a "quantidade" como objeto de estudo das matemáticas. Salientamos, porém, que há diferenças de âmbito filosófico entre essas duas classificações, as quais não aprofundaremos neste artigo. Contudo, destacamos que, para van Roomen (1602), as matemáticas mistas seguem a visão de mundo aristotélica, não se inserindo como ciências práticas, enquanto Bacon (1605, 2007) teve a pretensão de substituir a concepção aristotélica. Dessa forma, na filosofia baconiana, essas matemáticas foram abordadas como concernentes à vida prática, atribuindo uma nova visão a dicotomias como teoria e prática, contemplação e atividade e scientia e potentia.

\section{Considerações finais}

É importante mencionar que o conjunto das disciplinas matemáticas se desenvolvem, naquele período, em uma pluralidade:

"Não se trata apenas na pluralidade no sentido de que cada pessoa compreende um objeto de maneira diferente, mas antes no sentido de que se podia conceber a matemática não como um objeto, uma disciplina, mas como um conjutno de disciplinas relacionadas, as matemáticas, no plural.” (GONÇALVES, 2012, p. 33)

Isso é percebido na análise dos trechos das duas obras aqui mencionadas. Ao compararmos as classificações das matemáticas de Dee (1570) e de van Roomen (1602) podemos verificar que há algumas semelhanças entre os diversos conceitos que estão presentes em ambas, principalmente, em relação à Aritmética e à Geometria, que foram elencadas como parte das Matemáticas Principais.

As diferenças são mais evidentes no que se refere àquelas matemáticas relacionadas ao estudo de elementos do mundo físico. Dee considera que são Artes Matemáticas Derivadas das Principais, enquanto van Roomen mantém uma parte delas entre as Principais, porém, inseridas no campo das Matemáticas Mistas - decorrentes do estudo de entes naturais e produzidos independente de ações humanas - e outra parte compõe as Matemáticas Mecânicas - que buscam a compreensão da produção e da ação de instrumentos e máquinas. 
Podemos notar ainda que, tanto na classificação de Dee como na de van Roomen, há ciências e disciplinas que, apesar de lidar com elementos da matemática - é o caso, por exemplo, da Astronomia, Pneumática, Cosmografia, Geografia, entre outras -, atualmente constituem áreas de conhecimentos que não reconhecemos hoje como parte das matemáticas, mas que naquele período, ou seja, pelo menos na segunda metade do século XVI até o início do século XVII, eram entendidas como tais.

A partir da leitura e tradução desses excertos, percebemos que a questão de as matemáticas serem consideradas ciências ou não pode estar relacionada ao estatuto social daqueles que são chamados de matemáticos na época (BIAGIOLI, 1989; CAROLINO, 2007; MOTA, 2007; ROMANO, 2004). Embora os autores não falem especificamente sobre isso, talvez esse movimento do período em classificar o que seriam consideradas matemáticas teria relação com a busca de valorização desse status das pessoas envolvidas com essas artes/disciplinas, nas quais eles incluem uma grande diversidade de artes práticas e teóricas que vão além do quadrivium. De fato, Dee (1570) afirma que essas artes não tinham o seu devido crédito por não haver tratados anteriores ao seu que abordassem essa classificação e descrição das ciências matemáticas. Entretanto, essa é uma questão que deve ser abordada em um estudo posterior.

Conforme mencionamos anteriormente, estas classificações não podem ser compreendidas como predominantes nos séculos XVI e XVII, pois neste mesmo período, ocorrem intensos debates científicos e filosóficos que geraram importantes impactos no desenvolvimento das diversas áreas do saber. No que diz respeito às matemáticas, a álgebra, o cáculo diferencial e integral e a geometria análitica tem seu desenvolvimento justamente nos séculos XVI e XVII. Porém, ao apresentarmos as classificações de Dee e de van Roomen, mostramos que há também um debate mais amplo sobre quais conhecimentos devem ou não ser considerados parte das disciplinas matemáticas. Se em parte, as classificações de Dee e de van Roomen nos mostram a presença de uma tradição enraizada nos estudiosos da Antiguidade e do Medievo, também são essas mesmas classificações que nos apresentam como essas tradições estavam sendo questionadas, repensadas e reconfiguradas de forma a incorporar ideias contemporâneas.

Consideramos, então, que o estudo das classificações dos conhecimentos humanos, bem como das matemáticas, além de apresentar um panorama e a compreensão de quais eram os saberes de um determinado período, nos permite verificar os movimentos do pensamento científico/matemático no decorrer do tempo. Estes aspectos se tornam importantes na medida em que pesquisadores da área da história da matemática necessitam reconhecer o conhecimento matemático de cada período a partir de seus contextos culturais e filosóficos, evitando os anacronismos que buscam identificar o saber do presente no passado. 


\section{Bibliografia}

ALMEIDA, Bruno. 2012. On the origins of Dee's mathematical programme: The John Dee - Pedro Nunes connection. In: Studies in History and Philosophy of Science. Elsevier. Vol. 43, 460-469.

ALSTED, Johann Heinrich. 1630. Encyclopaedia septem tomis distincta. Herborn: George Corvini.

APOMECOMETRIA. 2021. In: Dicionário Michaelis. Disponível em: $<$ https://michaelis.uol.com.br/busca? $\mathrm{r}=0 \& \mathrm{f}=0$ \&t$=0$ \&palavra=apomecometria $>$ Acesso em: 4 jul. 2021.

ARISTÓTELES. 1995. Categorias. Tradução de Ricardo Santos. Porto: Porto Editora.

BACON, Francis. 1605, 2007. O progresso do conhecimento. Tradução, apresentação e notas Raul Filker. São Paulo: Editora Unesp.

BENNETT, Jim. 2013. How relevant is the category of 'mixed mathematics' to the sixteenth century? In: From "Mixed" to "Applied" Mathematics: tracing an important dimension of mathematics and its history. Oberwolfach report. 677-680.

BERTATO, Fábio Maia; D'OTTAVIANO, Ítala Maria Loffredo. 2007. Luca Pacioli and the 'Controversy of the Perpective': the classification of the mathematics from classical antiquity to the end of quattrocento. In: Revista Brasileira de História da Matemática, Especial no 1 - Festschrift Ubiratan D’Ambrosio, 505-525.

BIAGIOLI, Mario. (1989). The Social Status of Italian Mathematicians, 1450-1600. History of Science, vol. 27, $\mathrm{n}^{\circ}$ 1, 41-95.

BILLINGSLEY, Henry. 1570. The elements of geometrie of the most auncient Philosopher Euclide of Megara. Londres, John Day.

BOCKSTAELE, Paul Petrus. 1966. Roomen (Romanus, Romain), Adriaan (Adrianus) van. In: Nationaal Biografisch Woordenboek. Bruxelas, Paleis der Academiën, vol. 2, 751-755.

BOGNOLO, Marco. 1839. Panlessico Italiano. vol. 4. Veneza: Girolamo Tarso.

BOSMANS, Henri. 1907. Romain (Adrien). In. Biographie Nationale, vol. 19, 848-889.

BROMBERG, Carla. 2010. As Artes Liberais entre o Medievo e o Renascimento. In: M. H. R. Beltran, F. Saito, \& L. S. P. Trindade. (Eds.). História da Ciência: tópicos atuais 2. São Paulo: Editora Livraria da Física. 11-31. 
BROMBERG, Carla. 2011. Identificando Parâmetros para as Classificações das Ciências Liberais e Mecânicas no Renascimento Italiano. In: Anais do Congresso Scientiarum Historia IV. Rio de Janeiro: HCTE-UFRJ. 184-190.

BROWN, Gary I. 1991. The Evolution of the Term “Mixed Mathematics”. In: Journal of the History of Ideas, vol. 52, 81-102.

CAROLINO, Luis Miguel. (2007). Cristoforo Borri and the epistemological status of mathematics in seventeenth-century Portugal. In: Historia Mathematica. vol. 34, n 2. 187205.

DARNTON, Robert. 1986. O grande massacre dos gatos, e outros episódios da História Cultural francesa. Tradução de Sonia Coutinho. Rio de Janeiro: Graal.

DEAR, Peter. 2001. Revolutionizing the Sciences: European Knowledge and Its Ambitions, 1500-1700. Wales: Creative Print \& Design.

DEE, John. 1570. Mathematicall Praeface. In: BILLINGSLEY, Henry. The elements of geometrie of the most auncient Philosopher Euclide of Megara. Londres: John Day.

DE SMET, Antoine. 1990. Gérard Mercator (1512-1594) et les sciences occultes. In: Scientiarum Historia. vol. XVI, n ${ }^{\circ}$ 1-2, 5-10.

ESTRATARITMETRIA. 1793. In: Diccionario Castellano con las voces de ciencias y artes y sus correspondientes en las tres linguas francesca latina e italiana, vol. 4. Estevan Terreros y Pando.

GONÇALVES, Carlos Henrique Barbosa. 2012. A álgebra no século XVI. In: A. Muhana, M. Laudanna \& L. A. Bagolin. (Orgs.). Retórica. São Paulo: Annablume. 31-43.

GONÇALVES, Carlos Henrique Barbosa; OLIVEIRA, Zaqueu Vieira. 2007. Geometria, Reforma e Contra-Reforma na Carta de 1 de julho de 1597, de Adriaan van Roomen para Clavius. In: Circumscribere. Vol. 3. 11-19.

GONÇALVES, Carlos Henrique Barbosa; OLIVEIRA, Zaqueu Vieira. 2010. A atividade matemática de Adriaan van Roomen. In: Revista Brasileira de História da Matemática. vol. $10, n^{\circ} 20,147-164$.

GULLBERG, Jan. 1997. Mathematics: from the birth of numbers. New York: W. W. Norton.

HARROD, Henry. 1874. Report on the Deeds and Records of the Borough of King's Lynn. London: Thew \& Son. 
HIPSOMETRIA. 2021. In: Infopédia. Porto: Porto Editora. Disponível em <https://www.infopedia.pt/\$hipsometria>. Acesso em: 3 julho 2021.

HOLLAR, Wenceslaus. 1669. The Groundplat of Kanton. London (Acervo do Museu Britânico). Disponível em: <https://www.britishmuseum.org/collection/object/P_18550512-189>. Acesso em: 19 maio 2021.

JARRETT, Joseph. 2019. Mathematics and Late Elizabethan Drama. Cambridge: Palgrave Macmillan.

KAWAJIRI, Nobuo. 1979. Francis Bacon's View of Mathematics - Bacon concept of Mixed Mathematics. Proceedings of the Faculty of Science. vol. XV. Tokai University.

KNOBLOCH, Eberhard. 1989. Klassificationem. In: M. Folkerts (Ed.), Mass, Zahl und Gewicht - Mathematik als Schlüssel zu Weltverständnis und Weltbeherrschung. Weinheim: VCH, Acta Humaniora. 13-40.

MANDERS, Keneth. 2006. Algebra in Roth, Faulhaber, and Descartes. Historia Mathematica. n. 33. 184-209.

MOTA, Bernardo Machado. 2007. The Status of Mathematics in Portugal in the $16^{\text {th }}-17^{\text {th }}$ Centuries. HoST Journal of History of Science and Technology. vol. 1, pp. 183-194.

OLIVEIRA, Zaqueu Vieira. 2015. Uranografia ou a descrição do céu de Adriaan van Roomen. Coleção CLE. vol. 69. Campinas, Unicamp, Centro de Lógica, Epistemologia e História da Ciência.

OLIVEIRA, Zaqueu Vieira; HADDAD, Thomas Augusto Santoro. 2018. Adriaan van Roomen e sua Correspondência: desafios e controvérsias matemáticas no século XVI. In: Revista Brasileira de História da Matemática. vol. 18, n 36, 77-115.

PALKOSKA, Jan. 2007. The a priori in the Thought of Descartes: cognition, method and science. Cambridge: Cambridge Scholars Publishing.

RABOUIN, David. 2005. La “mathématique universelle” entre mathématique et philosophie, d’Aristotle à Proclus. Archives de Philosophie, n. 68. 249-268.

RABOUIN, David. 2009. Mathesis Universalis: l'idée de "mathématique universelle" d'Aristotle à Descartes. Paris: Presses Universitaires de France.

RAMPLING, Jennifer M. 2012. John Dee and the sciences: early modern networks of knowledge. In: Studies in History and Philosophy of Science, vol. 43, $\mathrm{n}^{\circ}$ 3, 432-436, Elsevier

BV.

Disponível

em: 
<https://www.sciencedirect.com/science/article/pii/S0039368111001129?via\%3Dihub>. Acesso em: 19 maio 2021.

ROMANO, Antonela. 2004. El estatuto de las matemáticas hacia 1600. In: Los orígenes de la ciencia moderna. Seminário Orotava de Historia de la Ciencia. Actas de los años XI y XII. Canarias: Consejería de Educación, Cultura y Deportes del Gobierno de Canarias. 277-308.

RULAND, Anton. 1867. Adrien Romanus, premier professeur à la faculté de médecine de Wurzbourg. In: Le Bibliophile belge. Bruxelas, vol. 2, 56-100, 161-187 e 256-269.

SAITO, Fumikazu. 2015. História da matemática e suas (re)construções contextuais. Sâo Paulo: Editora Livraria da Física.

SALES, Rodrigo de. 2016. Classificações bibliográficas e classificações arquivísticas: diferenças e semelhanças na organização do conhecimento. In: Scire, vol. 22, 65-77.

SALES, Rodrigo de. 2017. A Classificação de Livros de William Torrey Harris: influências de Bacon e Hegel nas classificações de biblioteca. In: Encontros Bibli: revista eletrônica de biblioteconomia e ciência da informação, vol. 22, nº 50. 188-204.

SASAKI, Chikara. 2004. Descartes's Mathematica Thought. New York: Springer.

SMITH, Charlotte Fell. 1909. John Dee. In: Nature. London: Constable and Co. Ltd., 121122.

SMITH, David Eugene. 1925. History of Mathematics: special topics of elementary mathematics. vol. 2. Dover Publications.

TABOADA, Nuñez de. s/d. Diccionario Francés-Español - Espaçnol-Framcés. Tomo I. Paris: Casa de Ch. Fouraut é Hijo.

VAN ROOMEN, Adriaan. 1591. Ouranographia sive caeli descriptio. Antuérpia: Johannes van Keerbergen.

VAN ROOMEN, Adriaan. 1602. Universae mathesis idea. Wurceburgo: Georgius Fleischmann.

VAN ROOMEN, Adriaan. 1605. Mathesis polemica. Frankfurt: Levinus Hulsius.

WEBER, Jean-Paul. 1964. Sur la Composition de la Regula IV de Descartes. In: Revue Philosophique de la France et de l'Étranger. No 154. 1-20. 
WEISHEIPL, James A. 1965. Classification of Sciences in Medieval Thought. In: Mediaeval Studies, vol. 27, 54-90.

WOLFE, Jessica. 2004. Humanism, Machinery, and Renaissance Literature. Cambridge: Cambridge University Press.

\section{Zaqueu Vieira Oliveira}

Universidade Federal da Integração Latino Americana - UNILA - Foz do Iguaçu - Brasil

E-mail: z.zaqueu@gmail.com

\section{Isabelle Coelho da Silva}

Pontifícia Universidade Católica de São Paulo PUC-SP - São Paulo - Brasil

E-mail: isabellecoelhods@gmail.com

\section{Kleyton Vinicyus Godoy}

Universidade Federal de Lavras - UFLA - Lavras - Brasil

E-mail: klegodoy@gmail.com 